\title{
Contribution to the translation and validation of the Adapted Illness Intrusiveness Ratings Scale for the Portuguese context
}

Contributos para a tradução e validação da escala Adapted Illness Intrusiveness Ratings no contexto português

Contribuciones para la traducción y validación de la escala Adapted Illness Intrusiveness Ratings en el contexto portugués

Elisabete Lamy da Luz*; Fernanda Santos Bastos**; Margarida Maria Silva Vieira***; Edgar Martins Mesquita***

\section{Abstract}

Background: The Adapted Illness Intrusiveness Ratings Scale was adapted and validated for the Portuguese context. Following the process of translation, its psychometric properties were measured with the purpose of assessing its validity and reliability.

Objectives: Translation and validation of the scale.

Methodology: The instrument was applied to a convenience sample of 271 people with chronic illness, aged 18-65 years, and living in Lisbon. An exploratory factor analysis was performed to assess its psychometric properties. The model proposed by the author was confirmed through confirmatory factor analysis.

Results: The factor analysis with Varimax rotation revealed three dimensions (Instrumental Activities, Intimacy, Relationships and Personal Development), which explained $73.24 \%$ of total variance. The scale showed an overall internal consistency of 0.92 .

Conclusion: The scale proved to be a reliable, valid, and useful tool to measure the perceived interference of chronic disease in people's lives.

Keywords: chronic disease; sickness impact profile; nursing assessment

\section{Resumo}

Enquadramento: A adaptação e validação da escala Adapted Illness Intrusiveness Ratings Scale é um estudo de tradução e medição das suas propriedades psicométricas, permitindo avaliar a sua validade e confiabilidade. Procedemos à sua adaptação e validação devido ao facto de não ter sido ainda realizado no contexto português.

Objetivos: Tradução e validação da escala.

Metodologia: $\mathrm{O}$ instrumento foi aplicado a uma amostra de conveniência de 271 pessoas com doença crónica, com idades compreendidas entre os 18 e os 65 anos residentes em Lisboa. Para avaliar as suas propriedades psicométricas recorreu-se a análise fatorial exploratória. Confirmou-se o modelo proposto pelo autor através da análise fatorial confirmatória.

Resultados: Da análise fatorial com rotação Varimax resultaram 3 dimensôes (Atividades Instrumentais, Intimidade, Relacionamento e Desenvolvimento Pessoal) explicando $73,24 \%$ da variância total. A escala revelou uma consistência interna global de 0,92.

Conclusáo: A escala mostrou ser um instrumento fiável, válido e útil para medir a perceção da interferência da doença crónica na vida das pessoas.

Palavras-chave: doença crónica; perfil de impacto da doença; avaliação em enfermagem

*MSc., Doctoral student, Universidade Católica Portuguesa, 1649-026, Lisboa, Portugal [luzelisabete10@gmail.com]. Contribution to the article: data collection, literature search, statistical treatment and evaluation, article writing and revision. Address for correspondence: Rua saraiva de carvalho $\mathrm{n}^{0} 342^{\circ}$ esq, 1250-244, Lisboa, Portugal.

**Ph.D. Adjunct Professor, Nursing School of Porto, 4200-072, Porto, Portugal [fernandabastos@esep.pt].Contribution to the article: statistical treatment and evaluation, data analysis, and discussion of results.

***Ph.D., Associate Professor, Universidade Católica Portuguesa, 4169-005, Porto, Portugal [mmvieira@porto.ucp.pt].Contribution to the article: data analysis and discussion.

****MSc., Doctoral student, Public Health Institute, University of Porto, 4780- 130, Santo-Tirso, Portugal [edgarmesquita@hotmail.com]. Contribution to the article: data analysis, treatment, statistical evaluation, and discussion.

\section{Resumen}

Marco contextual: La adaptación y validación de la escala Adapted Illness Intrusiveness Ratings Scale es un estudio de traducción y medición de sus propiedades psicométricas, lo que permite evaluar su validez y fiabilidad. Se ha procedido a su adaptación y validación debido a que todavía no se había realizado en el contexto portugués.

Objetivos: Traducción y validación de la escala.

Metodología: El instrumento se aplicó a una muestra de conveniencia de 271 personas con enfermedad crónica, con edades comprendidas entre los 18 y los 65 años y residentes de Lisboa. Para evaluar sus propiedades psicométricas se recurrió al análisis factorial exploratorio. Se confirmó el modelo propuesto por el autor a través del análisis factorial confirmatorio.

Resultados: Del análisis factorial con rotación Varimax surgieron 3 dimensiones (Actividades Instrumentales, Intimidad, Relación y Desarrollo), lo que explica el $73,24 \%$ de la varianza total. La escala reveló una consistencia interna global de 0,92 .

Conclusión: La escala mostró que es un instrumento fiable, válido y útil para medir la percepción de la interferencia de la enfermedad crónica en la vida de las personas.

Palabras clave: enfermedad crónica; perfil de impacto de enfermedad; evaluación en enfermería 


\section{Introduction}

Chronic illnesses have a major impact on self-concept and cause changes that occur during the diagnosis and extend throughout the treatment and subsequent periods. Patients' perception of this impact interferes with their ability to perform self-care and self-management of their therapeutic regimen, as well as with their self-efficacy and empowerment. The more intrusive is the disease, the more difficult it is to manage and incorporate the therapeutic regimen into the patients' daily lives. From this perspective, it is essential to assess the impact of chronic illness on patients' lives. This study aims to contribute to the translation and analysis of the psychometric properties of the Adapted Illness Intrusiveness Ratings Scale for the Portuguese context. Its availability in clinical practice will allow assessing the perceived impact of chronic illness on people's lives and understand how they experience this impact.

\section{Background}

The Illness Intrusiveness Ratings Scale was developed in 1983 (Devins et al., 1983) with the purpose of assessing the impact of the disease and treatment on the lives of people with chronic illness, which is one of the determinants that influence their quality of life and perceived empowerment. The scale was tested in patients with chronic illnesses such as endstage renal disease, multiple sclerosis, cancer, and rheumatoid arthritis (Novak, Mah, Zs, \& Devins, 2005), as well as in patients with psychiatric disorders (Carter, Bewell, \& Devins, 2008). The author of the scale published a more updated study on its validation and presenting three dimensions (Devins, 2010): Instrumental (1, 2, 3, 4, 5, 6); Intimacy $(7,8)$; and Relationships and personal development $(9,10,11,12,13)$.

This 13-item scale can be self-administered or administered by the researcher (Devins, 2010). In the Portuguese version, each item is rated on a 4 - point livert-type scale: 1 strongly disagree, 2 disagree, 3 agree, and 4 strongly agree. Higher scores indicate greater perceived interference of chronic illness in the person's life. This study aims to translate and validate the Adapted Illness Intrusiveness Ratings Scale into Portuguese. The general objective is to translate and validate the scale for subsequent use in the Portuguese context.

\section{Research questions}

Is the Classificaçâo Adaptada da Interferência da Doença Crónica (CAIDC) a valid and reliable scale for the Portuguese context?

\section{Methodology}

A quantitative, cross-sectional study was conducted to translate, back-translate, and validate the scale. The initial translation from English into Portuguese was performed by an English native speaker and the researcher/ supervisor. The scale was then back-translated into English by a person who had dual nationality (Portuguese and American) and another person of English origin who was born in Portugal. They did not know each other or the study. Subsequently, the translation was analyzed by a panel of experts.

After the linguistic and conceptual equivalence process, the Portuguese version of the scale was designated as Classificação Adaptada da Interferência da Doença Crónica (CAIDC). This version was pre-tested in 20 patients with chronic illness (Polit, 2004) from a convenience sample of 271 participants with chronic illness. These participants were selected from a Cluster of Healthcare Centers (ACES) of the Regional Health Administration of Lisbon and Tejo Valley (ARSLVT) between July 2014 and February 2015. Participants were recruited while using these health functional units. The criteria for inclusion in the sample were: both men and women aged 18 to 65 years, diagnosed with a chronic disease (diabetes, stroke, hypertension, asthma, chronic obstructive pulmonary disease, heart failure, rheumatoid arthritis, or lupus).

The sociodemographic characteristics of the sample revealed a mean age of 56 years $(S D$ $=8.5)$. Of the 271 participants, $118(43.5 \%)$ were men and 153 (56.5\%) were women. With regard to marital status, most of them 
were married or cohabiting (68.6\%). With regard to education, $35.4 \%$ of the respondents had completed the $4^{\text {th }}$ grade or less, $32.5 \%$ had completed the $5^{\text {th }}$ to $9^{\text {th }}$ grade, $21 \%$ had completed the $12^{\text {th }}$ grade, and $11.1 \%$ had completed higher education. The most common chronic illness among participants was hypertension $(80.1 \%)$ in association with other chronic diseases or per se.

\section{Study of validity and reliability}

For the study of the validity of the CAIDC, an exploratory factor analysis was performed using the principal components analysis and orthogonal Varimax rotation, and reliability was assessed through internal consistency. Reliability studies allow assessing the temporal stability and internal consistency or homogeneity of the items. Internal consistency was calculated using Cronbach's alpha coefficient, which is the most commonly used technique in case of multiple response options with different ratings as in the Likert scale (Fortin, 2009; Marôco, 2014b). In this study, the internal consistency or reliability of the scale revealed a Cronbach's alpha of 0.920 , which is considered a very good value (Hill \& Hill, 2008; Marôco, 2014b).

An exploratory factor analysis was performed. The Kaiser-Meyer-Olkin (KMO) measure was 0.882 and Bartlett's test $=2588,523$ for a $p<0.001$, which is considered a good level (Marôco, 2014b). A principal components analysis with Varimax rotation was then performed to identify the underlying and interdependent dimensions.

\section{Confirmatory factor analysis}

A confirmatory factor analysis (CFA) was performed to empirically test Devins' proposal. The CFA stands out from other validation processes because it is a specific type of structural equation modeling aimed at confirming the existence of inter-relationships between indicators (observed variables) belonging to a construct (latent variable).

In addition, it also aims to confirm that the latent variables may be correlated but should not suffer multicollinearity effects, i.e. they should not correlate with each other in such a way that they cannot be seen as independent variables (Brown \& Moore, 2012).

Therefore, the instrument should be able to measure each construct separately, but also measure all of the constructs in a consistent and interrelated manner (Marôco, 2014a; Schmitt, 2011).

The CFA followed the steps proposed by Jackson and Gillaspy (2009) and Marôco (2014a) in the model composed of three constructs: Instrumental activities - composed of six observed variables, CAI-1 to CAI-6; Intimacy - composed of two observed variables, CAI-7 and CAI-8; and Relationships and personal development - composed of five observed variables, CAI-9 to CAI-13. Thus, the model was composed of three latent variables with a total of 13 observed variables. Each correlation coefficient was estimated through the method of maximum likelihood, which presupposes multivariate normality (Bentler, 2006).

The model's fit to the data is a key indicator to validate the model for application in the population from which the sample was selected (Jackson \& Gillaspy, 2009). The following goodness-of-fit values and fit criteria were considered: a) Absolute fit indices that measure data fit to the theoretical model when compared to the saturated model (Marôco, 2014a). The chi-square test should be within the $95 \%$ confidence interval and the p-value should be greater than 0.05 . Since sample size is high in most cases, the p-value is, almost always, statistically significant. For this reason, it is common to divide the chi-square value by the number of degrees of freedom $(\chi 2)$ $g l)$ of the model, reducing the importance of sample size. The fit criterion is $\chi 2<3$ (Marôco, 2014a). The Root Mean Square Error of Approximation (RMSEA), with fit criteria below 0.07 (Marôco, 2014a; Schmitt, 2011) and pclose, which tests in a more sensitive criterion if the RMSEA value is below 0.05, with appropriate fit if $\mathrm{p}>0.05$ (Marôco, 2014a; Schmitt, 2011). The Goodness-of Fit-Index (GFI), with adequate fit greater than 0.90 (Hu \& Bentler, 1995; Marôco, 2014a); b) Incremental fit indices, which compare the proposed model with the null model (Brown $\&$ Moore, 2012) and presume the absence of inter-variable relations (Brown \& Moore, 2012). The Tucker Lewis Index (TLI) or non- 
normed fit index (NNFI), whose criterion is TLI/ NNFI > 0.90 (Brown \& Moore, 2012; Marôco, 2014a; Schmitt, 2011); c) Parsimonious fit indices, which compare the fit to the parameters necessary to obtain a specific fit (Brown \& Moore, 2012). Here, the Comparative Fit Index (CFI), whose criteri- on is CFI> 0.90 (Marôco, 2014a), and the Akaike Information Criterion (AIC), which indicates perfect fit when the value is null (Albright \& Park, 2009; Mesquita, 2013) were used.

Table 1 summarizes the goodness-of-fit criteria used in this study.

Table 1

Goodness-of-fit criteria used in the CFA

\begin{tabular}{lccc}
\hline Type of fit index & Fit index & Criterion & Source \\
\hline \multirow{2}{*}{ Absolute fit indices } & $\chi^{\wedge}$ /gl & $<3$ & Marôco, 2014a \\
RMSEA & $<0.70$ & Marôco, 2014a; Schmitt, 2011 \\
& GFI & $>0.90$ & Hu and Bentler, 1995; Marôco, 2014a \\
\hline Incremental fit indices & TLI/ NNFI & $>0.90$ & Brown and Moore, 2012; \\
\hline Parsimonious fit indices & CFI & $>0.90$ & Marôco, 2014a; Schmitt, 2011 \\
\hline
\end{tabular}

The correlations were assigned to the corresponding items in order to improve the model goodness-of-fit (Marôco, 2014a). All items used in the model were assessed based on the Mardia's coefficients of skewness and kurtosis. Then, the composite reliability (CR), the average variance extracted (AVE), the maximum shared variance (MSV), and the average shared variance (ASV) were computed.

Considering the potential redundancy in item 12 resulting from its high correlation with items 9 and 13, this item was deleted and another confirmatory analysis of the model was performed without item 12 .

\section{Ethical-legal principles}

The Ethics Committee of ARSLVT, IP issued a favorable opinion to the request to conduct the study. At the health functional units of the ACES, patients with chronic illness were explained the study objectives, the voluntary nature of their participation, and data anonymity. They were asked to give their informed consent and explained that they could withdraw from the study without any penalty. Only the patients who agreed to participate voluntarily in the study were asked to answer the questionnaire.

Additional information was provided before the questionnaire administration. Question- naires were completed by the researcher when patients used the health functional unit. Each questionnaire took about 25 minutes to complete.

\section{Results}

The results of the exploratory factor analysis showed that the items were divided into three factors, which explained $73.24 \%$ of total variance (Table 2). The first factor (items 1, 2, 3, 4,5 , and 6) is associated with the Instrumental activities of daily living, and has a Cronbach's alpha of 0.907 .

The second factor (items 7, 8, 9, and 10) reflects the impact of chronic illness on patients' relationships and intimacy, and has a Cronbach's alpha of 0.882 .

The third factor (items 11,12 , and 13) corresponds to the impact of chronic illness on human beings' potential for development, and has a Cronbach's alpha of 0.787 .

Factor loadings or commonalities were above 0.50 , so all items were maintained. The factor structure obtained in this study was very similar to the model proposed by Devins (2010). The dimension Instrumental activities was composed of the same items (I1, I2, I3, I4, I5, and I6) from the original model (Devins, 
2010); however, two items (I9 and I10) were transferred from the dimension Relationships and Personal Development to the dimension Intimacy.

Table 2

Principal components matrix after Varimax rotation of the 13 items of CAIDC

\begin{tabular}{|c|c|c|c|c|}
\hline & F1 & $\mathrm{F} 2$ & F3 & $h^{2}$ \\
\hline 1. Your feeling of being healthy & 0.828 & & & 0.75 \\
\hline 2. The things you eat and drink & 0.793 & & & 0.65 \\
\hline 3. Your work, including job, house work, chores, or errands & 0.832 & & & 0.82 \\
\hline 4. Playing sports, gardening, or other physical recreation or hobbies & 0.737 & & & 0.75 \\
\hline 5. Quiet recreation or hobbies, such as reading, TV, music, knitting & 0.686 & & & 0.66 \\
\hline 6. Your financial situation & 0.677 & & & 0.59 \\
\hline 7. Your relationship with your spouse or domestic partner & & 0.854 & & 0.82 \\
\hline 8. Your sex life & & 0.835 & & 0.79 \\
\hline 9. Your relationship and social activities with your family & & 0.583 & & 0.75 \\
\hline 10. Social activities with your friends, neighbors, or groups & & 0.617 & & 0.79 \\
\hline 11. Your religious or spiritual activities & & & 0.740 & 0.69 \\
\hline 12. Your involvement in community or civic activities & & & 0.839 & 0.74 \\
\hline 13. Your self-improvement or self-expression activities & & & 0.822 & 0.68 \\
\hline Variance per factor & 30.64 & 21.37 & 21.23 & \\
\hline
\end{tabular}

With regard to the CFA, this model showed adequate fit properties (Table 3$)$. The values of $\chi^{\wedge} 2 / \mathrm{gl}=2,71(<3), \mathrm{GFI}=0.91(>0.90)$, TLI $=0.95(>0.90)$, and CFI $=0.96(>0.90)$ met the established criteria. The AIC (224.65) was much lower than the one in the independent model (2665.02), which supports the fit of the model under analysis.

Table 3

Goodness-of-fit indices based on the CFA of the CAIDC

\begin{tabular}{ccc}
\hline Fit indices & Model goodness-of-fit & Fit criteria \\
\hline$\chi^{\wedge} 2 / \mathrm{gl}$ & 2.71 & $<3$ \\
RMSEA $(90 \%$ CI $)$ pclose & $0.08(0.65-0.09) \mathrm{p}<0.001$ & $<0.70 ;$ pclose $>0.05$ \\
GFI & 0.91 & $>0.90$ \\
TLI & 0.95 & $>0.90$ \\
CFI & 0.96 & $>0.90$ \\
AIC & $224.65<2665.02$ & \\
\hline
\end{tabular}

Finally, the unstandardized coefficients measure the impact of each item on the construct (Table 4). Firstly, it should be noted that all coefficients were statistically significant $(p<0.001)$. In the dimension Instrumental activities, items CAI 3 $(\beta=1.48)$ and CAI $4(\beta=1.43)$ showed par- ticularly high coefficients. With regard to the dimension Intimacy, item CAI $8(\beta=1.16)$ showed the highest value. Finally, in the dimension Relationships and personal development, items CAI $14(\beta=1.27)$ and CAI $9(\beta=1.21)$ showed the highest coefficients. 
Table 4

Estimated unstandardized coefficients of the Confirmatory Model

\begin{tabular}{llcccc}
\hline & & Estimate $(\beta)$ & SE & $Z$ & $p$-value \\
\hline CAI 1 & $\leftarrow$ Instrumental activities & 1.27 & 0.08 & 16.05 & $p<0.001$ \\
CAI 2 & $\leftarrow$ Instrumental activities & 1.08 & 0.09 & 12.04 & $p<0.001$ \\
CAI 3 & $\leftarrow$ Instrumental activities & 1.48 & 0.08 & 18.84 & $p<0.001$ \\
CAI 4 & $\leftarrow$ Instrumental activities & 1.43 & 0.08 & 17.72 & $p<0.001$ \\
CAI 5 & $\leftarrow$ Instrumental activities & 1.04 & 0.07 & 14.40 & $p<0.001$ \\
CAI 6 & $\leftarrow$ Instrumental activities & 1.19 & 0.09 & 13.32 & \\
CAI 7 & $\leftarrow$ Intimacy & 1.14 & 0.06 & 17.76 & $p<0.001$ \\
CAI 8 & $\leftarrow$ Intimacy & 1.16 & 0.07 & 17.14 & $p<0.001$ \\
CAI 9 & $\leftarrow$ Relationships and personal development & 1.21 & 0.06 & 20.84 & $p<0.001$ \\
CAI 10 & $\leftarrow$ Relationships and personal development & 1.18 & 0.06 & 20.77 & $p<0.001$ \\
CAI 1 & $\leftarrow$ Relationships and personal development & 0.65 & 0.05 & 12.95 & $p<0.001$ \\
CAI 12 & $\leftarrow$ Relationships and personal development & 0.46 & 0.05 & 10.36 & $p<0.001$ \\
CAI 13 $\leftarrow$ Relationships and personal development & 0.27 & 0.04 & 6.65 & $p<0.001$ \\
\hline
\end{tabular}

Note: $\mathrm{SE}=$ Standard Error.

The measurement model of the CFA of the CAIDC (Figure 1) shows that factor loadings ranged from 0.40 to 0.95 . In addition, the inter-dimension correlations were high $[0.64$ $0.67]$.

Based on the modification indices, as well as the underlying theoretical framework, correlations were established between errors e9-e12 and e12-e13. These correlations were assigned to the corresponding items in order to improve the model goodness-of-fit (Marôco, 2014a).
The skewness and kurtosis values of all items used in this model were within the range [-2; 2], which was not problematic. Even so, the level of significance of Mardia's coefficient for this model was lower than $0.05(Z>1.96)$, suggesting non-normality.

The correlation between the observed variables and the latent variables showed statistically significant estimates $(p<0.001)$, rejecting $\mathrm{H} 0$ : $\beta \mathrm{i}=0$ for all of them. This result suggests that all items contribute significantly to each latent variable.

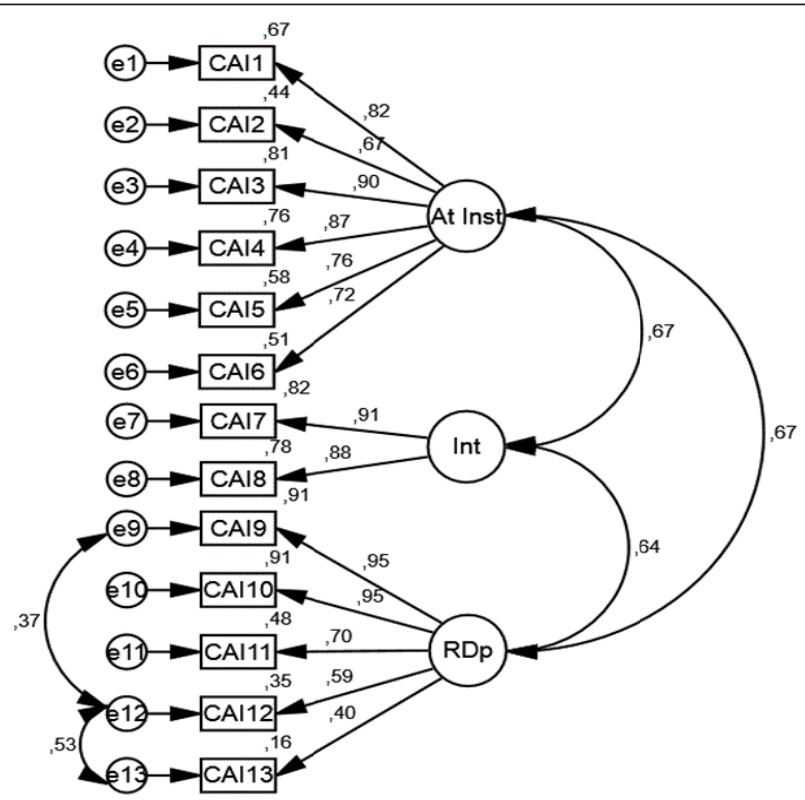

Figure 1. Measurement Model of the CAIDC. 
Then, CR, AVE, MSV, and ASV were calculated. The CR of each construct was greater than 0.70 , while the AVE was greater than 0.50 , which suggests both construct reliabili- ty and convergent validity.

As for discriminant validity, it was confirmed in all constructs because Both MSV and ASV were below the AVE (Table 5).

Table 5

$C R, A V E, M S V$, and ASV for the confirmatory model

\begin{tabular}{lllll}
\hline & CR & AVE & MSV & ASV \\
\hline Int & 0.89 & 0.80 & 0.45 & 0.43 \\
IAct & 0.91 & 0.62 & 0.45 & 0.45 \\
RpD & 0.85 & 0.56 & 0.45 & 0.43 \\
\hline
\end{tabular}

Nota . Int = Intimacy; IAct = Instrumental Activities; RpD = Relationships and Personal Development.

Considering the potential redundancy in item items 9 and 13, this item was deleted. All stan12 resulting from its high correlation with dardized coefficients were $\geq 0.40$ (Figure 2).

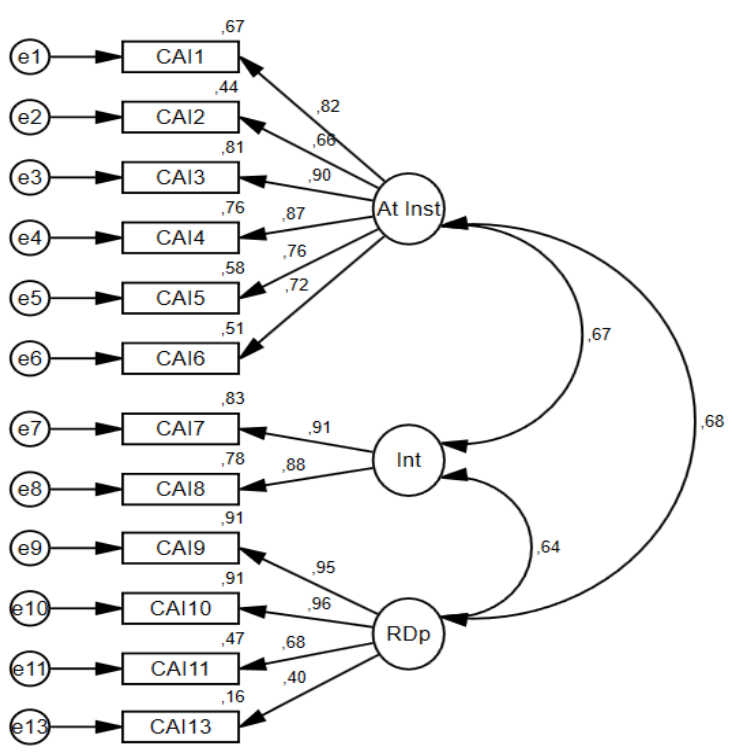

Figure 2. Measurement model of the CAIDC (without item 12).

With regard to the goodness-of-fit, the model showed a slight increase from 2.71 to 2.85 in (still within the $<3$ criterion) and from 0.91 to 0.92 in the GFI, when compared to the previous model. Due to the deletion of item CAI 12, the AIC decreased both in the final and saturated models, making it more parsimonious (Table 6). 
Table 6

Goodness-of-fit indices based on the CFA of the CAIDC

\begin{tabular}{ccc}
\hline Fit indices & Model goodness-of-fit & Fit criteria \\
\hline$\chi^{\wedge} 2 /$ gl & 2.85 & $<3$ \\
RMSEA $(90 \%$ CI $)$ & $0.08(0.07-0.09) p<0.001$ & $<0.70 ;$ pclose $>0.05$ \\
pclose & 0.92 & $>0.90$ \\
GFI & 0.95 & $>0.90$ \\
TLI & 0.96 & $>0.90$ \\
CFI & $199.38<2433.26$ & \\
AIC &
\end{tabular}

Similarly to the 13-item model, the skewness and kurtosis values of the 12 items used in this model were within the range $[-2 ; 2]$, which was not problematic. The level of significance of Mardia's coefficient for this model continued to be lower than $0.05(Z>$
1.96), suggesting non-normality.

The relations of the observed variables with the latent variables also showed statistically significant estimates $(p<0.001)$, rejecting $\mathrm{H0}: \beta \mathrm{i}=0$ for all of them. This result suggests that all items contribute significantly to each dimension (Table 7).

Table 7

Estimated unstandardized coefficients of the Confirmatory Model

\begin{tabular}{|c|c|c|c|c|c|c|}
\hline & & & Estimate $(\beta)$ & SE & $Z$ & $p$-value \\
\hline CAI 1 & $\leftarrow$ & Instrumental activities & 1.27 & 0.08 & 16.03 & $p<0.001$ \\
\hline CAI 2 & $\leftarrow$ & Instrumental activities & 1.08 & 0.09 & 12.01 & $p<0.001$ \\
\hline CAI 3 & $\leftarrow$ & Instrumental activities & 1.48 & 0.08 & 18.84 & $p<0.001$ \\
\hline CAI 4 & $\leftarrow$ & Instrumental activities & 1.43 & 0.08 & 17.73 & $p<0.001$ \\
\hline CAI 5 & $\leftarrow$ & Instrumental activities & 1.04 & 0.07 & 14.36 & $p<0.001$ \\
\hline CAI 6 & $\leftarrow$ & Instrumental activities & 1.19 & 0.09 & 13.30 & $p<0.001$ \\
\hline CAI 7 & $\leftarrow$ & Intimacy & 1.14 & 0.06 & 17.81 & $p<0.001$ \\
\hline CAI 8 & $\leftarrow$ & Intimacy & 1.16 & 0.07 & 17.10 & $p<0.001$ \\
\hline CAI 9 & $\leftarrow$ & $\begin{array}{l}\text { Relationships and personal } \\
\text { development }\end{array}$ & 1.20 & 0.06 & 20.75 & $p<0.001$ \\
\hline CAI 10 & $\leftarrow$ & $\begin{array}{l}\text { Relationships and personal } \\
\text { development }\end{array}$ & 1.18 & 0.06 & 20.88 & $p<0.001$ \\
\hline CAI 11 & $\leftarrow$ & $\begin{array}{l}\text { Relationships and personal } \\
\text { development }\end{array}$ & 0.63 & 0.05 & 12.61 & $p<0.001$ \\
\hline CAI 13 & $\leftarrow$ & $\begin{array}{l}\text { Relationships and personal } \\
\text { development }\end{array}$ & 0.27 & 0.04 & 6.63 & $p<0.001$ \\
\hline
\end{tabular}

Note: $\mathrm{SE}=$ Standard error.

The asymmetry and kurtosis values of all items used in this model are within the range $[-2 ; 2]$, which was not problematic. Even so, Mardia's coefficient for this model obtained a level of significance lower than $0.05(Z>1.96)$, suggesting non-normality.

As in the previous model, CR, AVE, MSV, and
ASV were calculated. The CR of each construct was greater than 0.70 , and the AVE was greater than 0.50 , which suggests both construct reliability and convergent validity.

As for discriminant validity, it was confirmed in all constructs because Both MSV and ASV were below the AVE (Table 8). 
Table 8

$C R, A V E, M S V$, and ASV for the confirmatory model (without item 12)

\begin{tabular}{lcccc}
\hline & CR & AVE & MSV & ASV \\
\hline Int & 0.89 & 0.80 & 0.45 & 0.43 \\
IAct & 0.91 & 0.63 & 0.46 & 0.46 \\
RpD & 0.85 & 0.61 & 0.46 & 0.43 \\
\hline
\end{tabular}

Nota . Int = Intimacy; IAct = Instrumental Activities; RpD = Relationships and Personal Development.

\section{Discussion}

In this study, the CAIDC was translated and validated using a sample of patients with chronic illness recruited from an ACES in the city of Lisbon. The exploratory factor analysis showed 13 items unequally distributed into three dimensions. This study revealed a Cronbach's alpha of 0.920 , a KMO measure of 0.882, and Bartlett's Test $=2588,523$ for a $p<0.001$. The Adapted Illness Intrusiveness Ratings Scale has been translated into English, French, German, Hungarian, Korean, German, and Spanish, and the process of translation and validation of the scale in other countries also showed these results (Novak et al., 2005). In addition, it showed an adequate cultural equivalence and robust psychometric properties. Since the CFA revealed an error between item 12 and items 9 and 13, item 12 was deleted, resulting in a model with a better fit. The only result that did not meet the established criteria was the RMSEA $=0.08$. Nevertheless, it should be noted that the RMSEA also exceeded the expected values in other studies (Molzon, Ramsey \& Suorsa, 2013).

\section{Conclusion}

The application of CAIDC to a sample of Portuguese patients showed that it has very good internal consistency and robust psychometric characteristics, the principal components analysis showed good unidimensionality and reliability, and the obtained factor structure is similar to the one found by Devins (2010). Therefore, the model was tested using the CFA, showing good fit indices in $\mathrm{IBM}^{\otimes} \mathrm{SPSS}^{\circledast}$ Amos structural equation modeling software. The CAIDC proved to be a reliable, valid, and useful tool for measuring the perceived impact of chronic illness on people's lives, and should be validated in Portuguese contexts.

\section{References}

Albright, J. J., \& H. M. Park. (2009). Confirmatory factor analysis using amos, LISREL, Mplus, and SAS/STAT CALIS. In The University Information Technology Services (UITS) Center for Statistical and Mathematical Computing, EUA: Indiana, 2008 (175). Indiana University.

Bentler, P. M. (2006). EQS 6 Structural Equations Program Manual. Encino, CA: Multivariate Software, Inc.

Brown, T. A., \& Moore, M. T. (2012). Confirmatory factor analysis. In R. Hoyle (Ed.), Handbook of structural equation modelling (pp. 361-379). New York, NY: The Guilford Press.

Carter, J., Bewell, C., \& Devins, G. (2008). Illness intrusiveness in anorexia nervosa. Journal of Psychosomatic Research, 64(5), 519-526. doi:10.1016/j. jpsychores.2008.01.001

Devins, G. M., Binik, Y. M., Hutchinson, T. A., Hollomby, D. J., Barré, P. E., \& Guttmann, R. D. (1983). The emotional impact of end stage renal disease: Importance of patient's perceptions of intrusiveness and control. International Journal of Psychiatry in Medicine, 13(4),327-343. doi:10.2190/5DCP-25BV-U1G9-9G7C

Devins, G. (2010). Using the illness intrusiveness ratings scale to understand health related quality of life in chronic disease. Journal of Psychosomatique Research, 68 (6), 591-602.

Fortin, M. (2009). Fundamentos e etapas do processo de investigação. Loures, Portugal: Lusodidacta.

Hill, M. M., \& Hill, A, (2008). Investigação por questionário. Lisboa, Portugal: Sílabo.

Hu, L. T., \& Bentler, P. M. (1995). Evaluating model fit. In R. H. Hoyle (Ed.), Structural equation modeling: Concepts, issues, and applications (pp. 76-99). Thousand Oaks, CA: Sage.

Jackson, D. L., \& Gillaspy, J. A. (2009). Reporting 
practices in confirmatory factor analysis: An overview and some recommendations. Psychological Methods, 14(1), 6-23. doi:10.1037/a0014694

Marôco, J. (2014a). Análise de equaçōes estruturais: Fundamentos teóricos, software \& aplicaçōes. Lisboa, Portugal: Sílabo.

Marôco, J. (2014b). Análise estatística com o SPSS Statistics. Loures, Portugal: ReportNumber.

Mesquita, E. (2013). Estudos bioestatísticos em leucemias mielóides agudas e linfomas (Dissertação de mestrado). Universidade do Minho, Escola de Ciências, Portugal.

Molzon, E., Ramsey, R., \& Suorsa, K. (2013). Using Factor structure of the ilness intrusiveness ratings scale in young adults with allergies and asthma. Journal of Asthma and Allergy Educators, 4(2). doi: $10.1177 / 2150129713478441$

Novak, M., Mah, K., Zs, M., \& Devins, G. (2005). Factor structure and reliability of the Hungarian version of the illness intrusiveness scale: Invariance across North American and Hungarian dialysis patients. Journal of Psychosomatic Research, 58(1), 103-110. doi:10.1016/j.jpsychores.2004.05.008

Polit, D, H. (2004). Fundamentos de pesquisa em enfermagem: métodos, avaliação utilização. Porto Alegre, Brasil: Artmed.

Schmitt, T. A. (2011). Current methodological considerations in exploratory and confirmatory factor analysis. Journal of Psychoeducational Assessment, 29(4), 304-321. doi:10.1177/0734282911406653 